\title{
ESTADO Y DERECHO DE EXCEPCIÓN. LA JURIDIFICACIÓN DEL PRINCIPIO LA NECESIDAD NO CONOCE REGLAS*
}

\author{
LEONARDO ÁLVAREZ ÁLVAREZ \\ Profesor Titular de Derecho Constitucional \\ Universidad de Oviedo
}

TRC, n. ${ }^{\circ} 48,2021$, pp. 315-341

ISSN 1139-5583

\begin{abstract}
SUMARIO
I. El concepto de excepción en la ciencia del derecho constitucional. II. La teoría del estado de excepción y el principio de necesidad como categoría autónoma. III. La teoría del derecho de excepción y la juridificación del principio de necesidad. IV. La construcción constitucionalmente adecuada del principio de necesidad en la CE. V. Conclusiones.
\end{abstract}

\section{EL CONCEPTO DE EXCEPCIÓN EN LA CIENCIA DEL DERECHO CONSTITUCIONAL}

\section{La distinción entre Estado y derecho de excepción}

La literatura española y la jurisprudencia del TC han venido utilizando las categorías de Estado de excepción y derecho de excepción para definir lo prescrito por los arts. 116 y $155 \mathrm{CE}^{1}$. Sin embargo, a pesar de que pudiera no parecerlo, los

* Quiero agradecer a Patricia García Majado, Profesora Ayudante Doctora de Derecho Constitucional de la Universidad de Oviedo, por el debate y por sus interesantes sugerencias aportadas para la elaboración de este trabajo. Realizadas desde su visión sobre las inmunidades del poder y del sistema jurídico, objeto de su tesis doctoral, aún inédita.

1 Y así, STC 83/2016, FJ. 7. ${ }^{\circ}$ afirmó que «Las previsiones del art. 116 CE han de completarse, para una adecuada delimitación del derecho de excepción en el texto constitucional de 1978, con el art. 55.1 CE». Por su parte, el ATC 40/2020, FJ. 4. ${ }^{\circ}$, reconoció «Desconocidas y, desde luego, imprevisibles cuando el legislador articuló la declaración de los estados excepcionales en el año 1981». En la literatura, sobre el empleo de estas 
conceptos estado/derecho de excepción expresan una contradicción en sus propios términos $^{2}$. En efecto, mientras el estado de excepción alude, en un sentido estricto, al derecho y al deber metapositivo del Estado a defenderse en caso de peligro existencial ${ }^{3}$, el derecho de excepción propone su plena positivación, construyéndolo en el interior del ordenamiento jurídico ${ }^{4}$.

La simple exposición de estos presupuestos metodológicos, hay que reconocerlo, podría servir de base para entender trasnochado el empleo de la categoría del estado de excepción en el derecho constitucional español, edificado sobre un concepto plenamente positivo de Constitución ${ }^{5}$. No obstante, las críticas, de ordinario, manifestadas en contra de la doctrina del estado de excepción de que es un razonamiento de derecho natural ${ }^{6}$ o que engloba un conjunto de consideraciones políticas revestidas en forma de norma jurídica ${ }^{7}$ han pasado con frecuencia por alto que aquella doctrina no ha podido ser juridificada totalmente por las teorías del derecho de excepción ${ }^{8}$. Quizás porque, como se ha puesto de manifiesto, la juridificación del estado de excepción implique, en realidad, una paradoja en sus propios términos?.

Sin embargo, lo cierto es que ni la doctrina del estado de excepción, como tampoco la del derecho de excepción — que propone su plena positivación-, pueden entenderse útiles para interpretar el contenido normativo de la excepción introducida por los enunciados de los arts. 116 y 155 CE en el derecho constitucional. Y

expresiones véase P. CRuz Villalón, Estados excepcionales y suspensión de garantías, Tecnos, Madrid, 1984, p. 19 y C. GARRIDo López, Decisiones excepcionales y garantía jurisdiccional de la Constitución, Marcial Pons, Madrid, 2021, pp. 90 y 91. Sobre el art. 155 CE, véase P. Cruz Villalón, «Experiencia y jurisprudencia de la coerción estatal (Artículo 155 CE)», Revista Española de Derecho Constitucional, n. ${ }^{\circ} 120,2020$, p. 19 y ss.

2 Véase Koja, P., Der Staatsnotstand als Rechtsbegriff, Anton Pustet, Salzburg, 1979, p. 8 y ss., 18 y ss.

3 Véase HüBER, E.-R., «Zur Lehre vom Verfassungsnotstand in der Staatstheorie der Weimarer Zeit» en H. Schneider y V. Götz (edits.), Im Dienst an Recht und Staat. Festschrit für Werner Weber zum 70 Geburtstag, Duncker \& Humblot, Berlin, 1974, p. 33.

4 Véase Koja, F., Allgemeine Staatslehre, Manz, Wien, 1993, p. 398.

5 Ya se manifestó en ese sentido P. Cruz Villalón en sus trabajos El estado de sitio y la constitución: la constitucionalización de la protección extraordinaria del estado, (1789-1878), Centro de Estudios Constitucionales, Madrid, 1980 y en Estados excepcionales y suspensión de garantías, op. cit. Imprescindible hoy para poder comprender los presupuestos teóricos de las doctrinas del estado de excepción es el treciente trabajo de J. de Miguel Bárcena y J. Tajadura Tejada, Kelsen «versus» Schmitt: política y derecho en la crisis del constitucionalismo, Guillermo Escolar, Madrid, 2018.

6 Véase Kelsen, H., Allgemeine Staatslehre, Max Gehlen, Berlin, 1925, p. 157.

7 Véase Giacometтı, Z., Das Staatsrecht der Schweizerischen Kantone, Schulthess Polygrapischer, Zürich, 1979 , p. 510.

8 Véase en ese sentido Huber, E.-R. «Zur Lehre vom Verfassungsnotstand in der Staatstheorie der Weimarer Zeit», op. cit., p. 39. En ese trabajo analizó criticamente los primeros intentos de juridificación de la doctrina del estado de excepción desarrollados durante la vigencia de la Constitución de Weimar de 1919 por parte del positivismo, como método científico imperante. Probablemente, como se verá, el fracaso de dichas teorías se ha arrastrado hasta la actualidad. Y se aprecia incluso en los representantes de las más relevantes y recientes contribuciones teóricas del derecho de excepción, anclados en los presupuestos del positivismo normativista. A pesar de que más adelante se analizarán críticamente tales contribuciones, puede verse por el momento F. Koja, Der Staatsnotstand als Rechtsbegriff, op. cit.

9 Véase Agamben, G., Estado de excepción. Homo sacer II, I, Adriana Hidalgo Editoria, Córdoba, 2004, p. 59 y ss. 
muy particularmente, el problema que plantea la no sujeción a las normas constitucionales —que se plasma en el art. 55,1 CE bajo la forma de suspensión-, en la que se materializa, por definición, cualquier excepción normativa. Sobre ello ha debatido intensamente la literatura española en los últimos tiempos ${ }^{10}$.

Como se tratará de demostrar a lo largo de este trabajo, a pesar de que las clásicas teorías del estado y del derecho de excepción han intentado explicar cuándo y de qué forma puede el Estado reaccionar frente a las situaciones que ponen en peligro su existencia misma, en el fondo, no son capaces de ejercer esa función adecuadamente. Las disfuncionalidades de las doctrinas sobre el estado de excepción se relacionan, sobre todo, aunque no solo, con la dificultad de distinguir conceptualmente entre excepcionalidad y normalidad ${ }^{11}$. Como se verá, parte de estos problemas podrían llegar a verse en el enunciado del art. $155 \mathrm{CE}$.

Por su parte, las teorías del derecho de excepción sí lograrán distinguir excepcionalidad y normalidad, dado que defienden — frente a la construcción metapositiva sobre el estado de excepción - la total positivación de la situación de excepción. Esto es lo que permitirá distinguir supuestamente entre una Constitución de excepción y una Constitución de la normalidad ${ }^{12}$, tesis que ha sido asumida por la literatura para interpretación de los arts. 116 y $155 \mathrm{CE}^{13}$. Sin embargo, como se tratará de demostrar, esta distinción resulta disfuncional ya que la preservación de la existencia del Estado en una concepción plenamente positiva de Constitución, como la que ha asumido la CE, solo puede ser coherentemente una función de una única Constitución: la Constitución de la normalidad. Esto no implica defender la paradoja de la juridificación de la excepción. En realidad, esta paradoja solo existe cuando la excepción y la normalidad son funciones de una norma del mismo rango constitucional.

A pesar de que pudiera no parecerlo, nuestra CE podría ofrecer apoyo normativo para la construcción de una teoría de la excepción capaz evitar las disfuncionalidades expuestas en las que incurren las doctrinas sobre el estado y del derecho

10 Entre muchos otros, véanse los trabajos de AláEz Corral, B., «Suspensión general de los derechos fundamentales» en L. López Guerra y E. Espín Templado (coords.), La defensa del Estado, Tirant lo Blanch, Valencia, 2004, p. 233 y ss., ReQuejo RodríGueZ, P., «¿Suspensión o supresión de los derechos fundamentales?», Revista de Derecho Político, n. ${ }^{\circ}$ 51, 2001, p. 105 y ss. En la literatura más actual pueden verse, a título de ejemplo, Presno Linera, M.A., «El derecho de reunión durante el estado de alarma sanitaria por Covid-19», F. J. Díaz Revorio, «Desactivando conceptos constitucionales: la suspensión de derechos y los estados excepcionales» e I. GómEZ FERNÁNDEZ, « ¿Limitación o suspensión? Una teoría de los límites a los derechos fundamentales para evaluar la adopción de estados excepcionales». Todos ellos publicados en la obra coordinada por C. GARRIDO LóPEZ, Excepcionalidad y derecho: el estado de alama en España, Fundación Giménez Abad, Zaragoza, 2021.

11 Véase BöCKENFÖRDE, E.-W., «Ausnahmerecht und demokratischer Rechtsstaat» en H. J. VoGEL, H. Simons y A. Podlech (edits.), Die Freibeit des Anderen. Festschrift für Martin Hirsch, Nomos, Baden-Baden, 1981 , p. 264 y 265.

12 Esa ha sido precisamente una de las características definitorias de las doctrinas sobre el derecho de excepción. Véase al respecto F. Ermacora, Allgemeine Staatslehre, Band II, Duncker \& Humblot, Berlin, 1970, p. 858 y ss., F. Koja, Der Staatsnotstand als Rechtsbegriff, op. cit., p. 14, Z. GiacomeTti, Das Staatsrecht der Schweizerischen Kantone, op. cit., p. 508.

13 Véase P. Cruz Villalón, Estados excepcionales y suspensión de garantías, op. cit., p. 19. 
de excepción. Explicando, en primer lugar, de qué manera el derecho constitucional puede distinguir adecuadamente entre excepcionalidad y normalidad — soslayando el problema de las teorías del estado de excepción-y, segundo, cómo ello puede llevarse a cabo a partir de la única Constitución existente: la Constitución de la normalidad — en lo que fallan las doctrinas del derecho de excepción-. A ello se dedican las siguientes páginas.

\section{La excepción y el principio la necesidad no conoce reglas}

En orden a poder construir una teoría constitucionalmente adecuada sobre la excepción, lo primero que debe de analizarse es qué es lo que define la excepción en el derecho público. Muchas teorías han recurrido para ello a las tradicionales máximas salus populi suprema lex esto, neccesitas non babet legem o inter arma silent leges $^{14}$. Estas expresiones, en realidad, vienen a ponen de manifiesto los dos elementos presentes en el concepto de excepción: la idea de necesidad y la no sujeción a las normas ${ }^{15}$. En efecto, como pusiera de relieve la teoría clásica del Estado, la excepción supone que, ante la necesidad de salvaguardar el Estado, desaparecen los límites impuestos ordinariamente a su poder ${ }^{16}$.

Sin embargo, para poder delimitar de una manera adecuada el significado de la excepción es imprescindible aclarar la relación existente entre los elementos de la necesidad y de no sujeción a las normas ${ }^{17}$. Y es que existen ocasiones en las que la idea de necesidad puede aparecer como fundamento de una regulación jurídica específica-principio la necesidad crea sus propias reglas - sin que ello legitime, en sentido estricto, una falta de sujeción a las normas constitucionales ${ }^{18}$. Eso es lo que parece suceder en el art. 86,1 CE, donde la extraordinaria y urgente necesidad justifica la previsión de órganos y procedimientos, que operan como una lex specialis, pero no introduce una excepción al deber de sujeción del art. 9,1 CE ${ }^{19}$.

14 Véase S. Verosta, «Das Staatsnotrecht», Österreichische Zeitschrift für öffentliches Recht, vol. 4, n. ${ }^{\circ} 9$, 1958 , p. 464.

15 Véase A. MenZel, «Zur Lehre von der Notverordnung» en Staatsrechtliche Abhandlungen: Festgabe für Paul Laband zum fünfzigsten Jabrestage der Doktor-Promotion, Band I, Keip, Frankfurt am Main, p. 369 y ss.

16 Véase O. Mayer, Deutsches Verwaltungsrecht, Duncker \& Humblot, Berlin, 2004, p. 11.

17 Véase al respecto el trabajo de V. Álvarez García, El concepto de necesidad en derecho público, Cívitas, Madrid, 1996, p. 327.

18 Véase G. Agamben, Estado de excepción, op. cit., p. 60.

19 A pesar de ello, una de las más relevantes teorías desarrolladas sobre el derecho de excepción ha tratado de ser aplicadas al derecho comparado. Y precisamente con ocasión del estudio de la Constitución Española de 1978, ha afirmado que el art. 86,1 CE sería precisamente la plasmación de una situación de excepción. Lo que ello parece indicar es que el concepto de excepción se construye a partir del principio la necesidad crea sus propias reglas. Se erige en fuente de nuevos órganos y procedimientos de creación de normas que aparecen como lex specialis frente a los órganos y los procedimientos de la normalidad. Véase F. Koja, Allgemeine Staatslehre, op. cit., p. 401 y 402. Sin embargo, se verá como el concepto de excepción presupone adicionalmente el principio la necesidad no conoce reglas. 
El art. 86,1 CE podría considerarse, por tanto, la plasmación juridificada del principio la necesidad crea sus propias reglas, pero no del principio de la necesidad no conoce reglas, que es lo que define, en realidad, la esencia de la excepción ${ }^{20}$. Este principio sí puede verse en el enunciado del art. 55,1 CE que autoriza expresamente al Estado a no sujetarse a determinadas reglas —a lo que se alude en él formalmente con el concepto de suspensión — vigentes en situaciones de normalidad cuando se declaren los estados de excepción y de sitio previstos en los arts. 116,3 y 4 CE.

Sin embargo, hay que reconocer que en los arts. 116, 3 y $4 \mathrm{CE}$ —al igual que sucede en el art. 86,1 CE- la necesidad también aparece legitimando la creación de sus propias reglas. Así lo deja claro el art. 1,1 LOAES, al afirmar que cabe declarar los estados excepcionales del art. 116 CE cuando los órganos y los procedimientos ordinarios resulten insuficientes para afrontar la situación planteada. Y lo hace para introducir una regulación orgánica y procedimental para la situación excepcional ${ }^{21}$. En realidad, la función del principio la necesidad no conoce reglas es justamente permitir la sustitución de una cierta regulación jurídica — cuya sujeción queda exonerada (art. 55,1 CE) — por otra basada en el principio de necesidad, que legitima la creación de sus propias reglas (art. $116 \mathrm{CE})^{22}$.

De lo aquí expuesto cabe deducir que el concepto de excepción ha de construirse, en realidad, a partir del principio la necesidad no conoce reglas. Sin embargo, sería necesario definir cuál debe de ser naturaleza de estas reglas, cuya sujeción resulta exceptuada para que su regulación pueda ser sustituida por otra basada en el principio de necesidad. Esto aparece justificado por la distinción que ha manejado la literatura entre la excepción constitucional y excepción legislativa ${ }^{23}$, en la que han puesto tradicionalmente su énfasis las máximas citadas neccesitas non babet legem o inter arma silent leges.

En una ciencia del derecho constitucional que se construya a partir de un concepto de Constitución como norma suprema, como sucede con la CE, la excepción solo puede significar lógicamente una excepción a la sujeción de normas constitucionales. Es decir, cuando el principio la necesidad no conoce reglas tiene

20 En efecto, la no sujeción a las normas, ya se verá de qué forma, es lo que define la esencia de la excepción, véase R. VoN MOHL, Das deutsche Reichstaatsrecht. Rechtliche und politische Eröterungen, Laupp'schen Buchhandlung, Tübingen, 1873, p. 92 y ss., C. F. Von Gerber, Grundzüge des deutschen Staatsrechts, Bernhard Tauschnitz, Leipzig, 1880, p. 41 y 42. Es decir, el principio la necesidad no conoce reglas. Acerca de este principio véase J. KOHLER, «Das Notrecht», Archiv für Rechts- und Wirtschaftsphilosophie, Vol. VIII, n. ${ }^{\circ} 4$, 1915 , p. 27 y ss.

21 Véase A. Arroyo Gil, «La naturaleza del estado de alarma y su presupuesto habilitante» en C. GARRIDO López (coord.), Excepcionalidad y derecho: el estado de alarma en España, Fundación Giménez Abad, Zaragoza, 2021, p. 48 y ss.

22 Sin perjuicio de que más adelante se analizará el verdadero sentido de esta conjunción de principios, véase por el momento el trabajo de B. AlÁEz CoRral, «Suspensión general de los derechos fundamentales», op. cit., p. 234, que afirma que el art. 55,1 CE permitiría al poder público de los arts. 116,3 y 4 CE operar como si la regulación jurídica constitucional no existiera.

23 Cfr. E.-W. BöCKENFÖRDE, «Das verdrängte Ausnahmezustand», Neue Juristische Wochenschrift, 1978 , p. 1881. 
por objeto reglas constitucionales. Eso es lo que sucede precisamente en el art. 55,1 $\mathrm{CE}$, que exonera de la sujeción a ciertos derechos fundamentales ${ }^{24}$. En el derecho constitucional carecería de sentido introducir una excepción a la sujeción a normas infraconstitucionales, que podría tener su fundamento directamente en la ley. Esto tiene relevancia en orden a interpretar el art. 155,1 CE.

El art. 155,1 CE carecería de sentido si se entendiera que el Estado puede no sujetarse a las normas de rango de ley a las que aluden los arts. 147 y $150 \mathrm{CE}$, que cumplen la función de distribuir territorialmente el poder ${ }^{25}$. Una posibilidad tal podría encontrarse reconocida perfectamente al nivel de la ley. Si el art. 155,1 CE se plasma en la Constitución ha de ser coherentemente para introducir una excepción a la sujeción a las normas constitucionales. En definitiva, para erigirse en la plasmación del principio la necesidad no conoce reglas constitucionales.

\section{LA TEORÍA DE ESTADO DE EXCEPCIÓN Y EL PRINCIPIO DE NECESIDAD COMO CATEGORÍA AUTÓNOMA}

\section{El fundamento del principio de necesidad}

Tres son las características que podrían servir para definir las doctrinas sobre el estado de excepción: a) la distinción conceptual entre el Estado y el derecho, b) la incapacidad del derecho, en todo o en parte, para regular la situación de excepción y c) la construcción del principio de necesidad como categoría jurídica autónoma. En efecto, aquellas teorías se construyen originariamente sobre la base de un concepto de Estado - aún vigente en la actualidad para la interpretación de la excepción en el derecho constitucional- ${ }^{26}$, que, como manifestación de la fuerza, se autolegitima para la realización de sus fines a través del sometimiento al derecho creado por él mismo ${ }^{27}$. De esto es posible deducir — puede ya avanzarse- que el Estado podrá desasirse coherentemente de su vinculación al derecho cuando éste resulte incapaz de garantizar el cumplimiento de sus fines ${ }^{28}$.

24 Efectivamente, así lo reconoce B. AlÁEz Corral, «Suspensión general de los derechos fundamentales», op. cit., p. 235.

25 Sobre el estado de la cuestión acerca de cuáles son las normas dispensadas de sujeción por el ejercicio del poder de coerción estatal véase el número monográfico de la Revista Española de Derecho Constitucional, 120,2020 .

26 Véase K. Stern, Das Staatsrecht der Bundesrepublik Deutschland, Band II, CH Beck, 1980, p. 1336.

27 Véase R. Von Hiering, Der Zweck im Recht, Band. I, Breitkopf \& Härtel, Leipzig, 1877, p. 321 y ss. No cabría desconocer, como han señalado algunos autores, la influencia que ha tenido el principio monárquico en el desarrollo de esta construcción sobre el estado de excepción. Véase Z. GiacometTi, Das Staatsrecht der Schweizerischen Kantone, op. cit, p. 509 y 510.

28 Habría que distinguir, efectivamente, aquí las clásicas teorías del estado de excepción centradas en el concepto de Estado y las que se apoyan en el concepto de Constitución. Así lo apunta A. JAKAB, «Das Grunddilemma und die Natur des Staatsnotstandes. Eine deutsche Problematik mit ausländischen Augen», 
Y justamente la segunda característica de las doctrinas sobre el estado de excepción es la incapacidad del derecho para poder regular la situación de excepción. Para justificarlo ha sido frecuente recurrir a dos tradicionales argumentos: a) bien que las normas del derecho carecen de la fuerza suficiente para afrontar los momentos críticos de la vida del Estado ${ }^{29} \mathrm{o}$ b) que presuponen una normalidad ausente en la situación excepción ${ }^{30}$. Esto es lo que ha llevado a desarrollar una teoría de las lagunas en el derecho ${ }^{31}$ que, como se verá más adelante, puede ser de gran utilidad para poder construir una teoría constitucionalmente adecuada de la excepción en el derecho constitucional y evitar sus disfuncionalidades. En este punto, en la literatura ha sido posible identificar dos grandes posiciones.

Por un lado, algunas doctrinas han defendido la existencia de una laguna completa en el derecho, ya que éste, por su propia definición, no puede ser capaz de regular la situación de excepción ${ }^{32}$. El derecho, en tanto conserve su eficacia generalizada, sí podría responder ante la infracción de sus normas, pero no podría hacer frente supuestamente ante situaciones que pusieran el peligro su eficacia misma e implicaran su propia negación, como sucede en la situación de excepción. Es aquí donde se encuadra la conocida teoría sobre la paradoja del derecho de excepción: la juridificación de algo injuridificable, como se muestra en ciertos textos constitucionales ${ }^{33}$.

Mayor interés presentan seguramente las doctrinas que han admitido la existencia de una laguna parcial en el derecho. El derecho puede y debe de regular la excepción, pero, dado que se trata de una situación impredecible, no podría ser capaz de regularla en todos sus extremos ${ }^{34}$. Esta laguna parcial en el derecho de excepción podría verse en el art. 116 CE que no define ni el supuesto de hecho ni las consecuencias jurídicas de los estados de alarma, excepción y sitio. Pero también en el art. 155 CE que alude a la posibilidad de adoptar las medidas necesarias, sin definir su contenido. Con una dicción, por cierto, muy similar a las normas constitucionales sobre las que se construyó originariamente la teoría sobre el estado de excepción ${ }^{35}$.

Kritische Justiz, Vol. 38, n. ${ }^{\circ}$ 3, 2005, p. 329 y ss. Véase también del mismo autor European constitutional language, Cambridge University Press, Cambridge, 2016, p. 314 y ss.

29 Véase G. JellineK, Allgemeine Staatslehre, Springer, Berlin, 1921, p. 358 y 359.

30 Véase C. Schmitт, Politische Theologie. Vier Kapitel zur Lehre der Souveranität, Duncker \& Humblot, Berlin, 1934, p. 19 .

31 Véase K. Stern, Das Staatsrecht der Bundesrepublik Deutschland, op. cit., p. 1334 y ss.

32 Véase H. KRüGER, Allgemeine Staatslehre, Kohlhammer, Sttutgart, 1966, p. 31.

33 Sobre la paradoja del derecho de excepción véase G. AgAmben, Estado de excepción, op. cit., p. 59. Esta paradoja se pondría de manifiesto, como mantiene el citado autor, en el art. 20,4 de la Constitución de Alemania, al disponer «Contra cualquiera que intente eliminar este orden (democrático liberal) todos los alemanes tienen el derecho de resistencia cuando no fuere posible otro recurso».

34 Véase al respecto E.-W. BöcKEnFöRdE, «Das verdrängte Ausnahmezustand», op. cit., p. 1885.

35 Véase, en particular, en el art. 14 de la Carta francesa de 1814, en el que se disponía «el rey es el jefe supremo del Estado... y dicta los reglamentos y ordenanzas necesarias para la ejecución de las leyes y la seguridad del Estado». Para J. Hatschek, es en dicha disposición en la que ha de verse el precedente 
Precisamente ante la incapacidad del derecho para regular en todo o en parte la situación de excepción, las doctrinas del estado de excepción construirán el principio metapositivo de necesidad de salvaguardar el Estado como categoría autónoma. Como se ha afirmado, es en caso de necesidad cuando las fuerzas naturales del Estado ocupan el espacio vacío del derecho ${ }^{36}$, permitiendo que cualquier órgano con capacidad de actuar, intervenga para preservar el Estado haciendo lo necesario en la situación dada ${ }^{37}$. Como se puede constatar, la necesidad aparece como la canalización de la fuerza normativa de lo fáctico, como la manifestación de la fuerza del Estado ante la incapacidad del derecho para satisfacer sus fines de autopreservación. En realidad, la necesidad aparece como el modo en el que se resuelve la contradicción lógica entre deber de preservar el Estado y el de sujetarse a las normas del derecho ${ }^{38}$.

Es fácil constatar de estas afirmaciones cómo para las teorías sobre el estado de excepción la necesidad — la fuerza normativa de lo fáctico-crea sus propias reglas. En este punto habría que plantearse si el TC no se ha aproximado, de alguna manera al modelo del estado de excepción en su STC 83/2016, al atribuir fuerza de ley a la declaración y prórroga del estado de alarma del art. 116,2 CE (FJ 10. ${ }^{\circ}$ ). Bastaría con recurrir a las construcciones del estado de excepción para apreciar que la causa de la fuerza de ley de las denominadas ordenanzas de necesidad para desplazar la aplicación de la ley aparece como el resultado de la fuerza normativa de lo fáctico ${ }^{39}$.

Pero igualmente podría suscitarse alguna duda de si lo afirmado por la STC 89/2019, con relación a la interpretación del art. 155 CE, no sería más compatible con las teorías sobre el estado de excepción, al erigir al principio de necesidad en parámetro interpretativo de la cláusula relativa a las medidas necesarias (FJ. 11. $\left.{ }^{\circ}\right)$. Y no el principio de proporcionalidad, en el que se ha materializado la necesidad en las doctrinas sobre el derecho de excepción, como resultado de la

de las ordenanzas de necesidad en el derecho público alemán y el punto de partida de la construcción teórica del estado de excepción. Véase «Der Ursprung der Notverördnung. Ein Beitrag zur Receptionsgeschichte des englische Staatsrechts», Zeitschrift für das Privat und öffentliche Recht der Gegenwart, 1900, p. 1 y ss.

36 «Si la Constitución, en tales casos, omite el derecho del gobierno a sustituir la voluntad del legislador, crea con ello una de aquellas situaciones que deben de evitarse y donde la eficacia de las fuerzas naturales del Estado ocupan el espacio vacío del derecho. El gobierno aquí, obligado por la fuerza de las circunstancias, actúa bajo su propia responsabilidad en caso necesario con los medios existentes», G. JeLLINEK, Gesetz und Verördnung. Staatsrechtliche Untersuchungen auf rechtsgeschichtlicher und rechtsvergleichender Grundlage, Mohr, Freiburg, 1887 , p. 348.

37 Véase K. Stern, Das Staatsrecht der Bundesrepublik Deutschland, op. cit., p. 1336.

38 Efectivamente, el estado de necesidad se ha definido como «el conjunto de mecanismos extraordinarios destinados a salvaguardar el Estado en supuestos de colisión». Una colisión que enfrenta, por un lado, el deber del Kaiser de «preservar el imperio alemán... y de observar los medios prescritos por las leyes». Véase C. G. BIEner, Die Bestimmung der Kaiserliche Macht-Vollkommenheit in der Teutschen Reichs-Regierung, Paul Gotthelf Kummer, Leipzig, 1780, p. 74.

39 Véase A. Menzel, «Zur Lehre von der Notverordnung», op. cit., p. 376. También también E.-W BÖCKENFÖRDE, «Das verdrängte Ausnahmezustand», op. cit. p. 1890. 
plena positivación del principio metapositivo de necesidad ${ }^{40}$. Criticas al respecto no han faltado en la literatura española ${ }^{41}$.

Para las teorías del estado de excepción, el principio la necesidad crea sus propias reglas — fundamentadas en la fuerza normativa de lo fáctico - tiene como lógica contrapartida el principio la necesidad no conoce las reglas del derecho, que se ha traducido en la posibilidad de que éstas, según las distintas construcciones, puedan ser infringidas ${ }^{42}$ o suspendidas en su aplicación ${ }^{43}$. En términos de aplicabilidad ha interpretado la práctica totalidad de la doctrina el concepto de suspensión de derechos fundamentales contenida en el art. 55,1 CE CE $^{44}$ Sin embargo, habría que plantearse si ello podría ser compatible una plena juridificación de la excepción. Más adelante se volverá sobre ello.

\section{Disfuncionalidades de la teoría del estado de excepción}

Como se ha podido apreciar, en el orden constitucional español pudieran atisbarse ciertos vestigios de la doctrina del estado de excepción. Y lo cierto es que hay que reconocer que algunos de sus elementos, como se verá más adelante, podrían coadyuvar a construir una teoría sobre la excepción en el derecho constitucional positivo. Sin embargo, buena parte de ellos son disfuncionales para ello. No podrían desconocerse los problemas vinculados a la concreción de cuándo surge la idea de necesidad de salvaguardar el Estado, que se ha deducido de una indeterminada construcción acerca de los fines de Estado ${ }^{45}$. No obstante, quizás el mayor problema en el que incurren las doctrinas sobre el estado de excepción es la dificultad de distinguir entre la excepcionalidad y la normalidad. Algo requerido por la situación de excepción, cuya función es precisamente retomar la normalidad $^{46}$.

40 Véase F. Koja, Der Staatsnotstand als Rechtsbegriff, op. cit., p. 64.

41 Véase al respecto J. García RocA, "Il tempo moderato” de la intervención coercitiva del Estado (artículo155 CE) en Cataluña: un comentario a las SSTC 89 y 90/2019, en particular, proporcionalidad y test de necesidad o razonabilidad de las medidas», Teoría y Realidad Constitucional, n. ${ }^{\circ} 44,2019$, p. 503.

42 Sobre las construcciones clásicas apoyadas en el concepto de Estado véase J. C. BuntsCHLI, Allgemeines Staatsrecht. Band II, J. G. Colta, München, 1868, p. 112. En lo que se refiere a las construidas a partir del concepto de Constitución, véase C. SCHмIT, Die Diktatur. Von den Anfängen des modernen Souveranitätsgedankens bis zum proletarischen Klassenkampf, Duncker \& Humblot, Berlin, 1978, p. 11.

43 Véase C. Sснмітт, Legalität und Legitimität, Duncker \& Humblot, Berlin, 1988, p. 58 y ss.

44 Véase en la literatura, entre muchos otros, P. REQUejo RodRíGUEZ, «Artículo 55» en M. Rodríguez Piñero y Bravo Ferrer - M. E. Casas Bahamonde, Comentarios a la Constitución Española. Tomo I, Wolters Kuwer y otros, Madrid, 2018, p. 1522.

45 Efectivamente, entre muchos otros, véase R. Von Hiering, Der Zweck im Recht, Band. I, op. cit., p. 321 y ss., C. G. Biener, Die Bestimmung der Kaiserliche Macht-Vollkommenheit in der Teutschen Reichs-Regierung, op. cit., p. 74, J. C. BunTsCHLI, Allgemeines Staatsrecht. Band II, op. cit., p. 112 y O. MAYER, Deutsches Verwaltungsrecht, op. cit., p. 11.

46 Véase A. JakAB, «Das Grunddilemma und die Natur des Staatsnotstandes. Eine deutsche Problematik mit ausländischen Augen», op. cit., p. 323 y 324. 
Esto ha sido, en realidad, la consecuencia de la ausencia de una construcción efectiva de una teoría sobre los límites de la excepción ${ }^{47}$. De esta forma, la normalidad corre el peligro que quedar, por así decir, absorbida por la excepcionalidad, sin que pueda garantizarse el adecuado retorno a la normalidad, que constituye precisamente la justificación de su existencia ${ }^{48}$. Una teoría de los límites a la situación de excepción solo puede ser posible a partir del derecho positivo. Por ello, la positivación del derecho constituirá un presupuesto para construir la excepción en la ciencia del derecho constitucional.

Para poder distinguir adecuadamente entre excepcionalidad y normalidad, sería necesario satisfacer, al menos, tres requisitos dentro del sistema jurídico: a) la existencia de un acto normativo expreso que defina el tránsito de la normalidad hacia la excepcionalidad, b) la limitación de la vigencia de la excepcionalidad, que implique la reinstauración de la normalidad —el principio de reversibilidad de la excepción- - y c) la limitación de las concretas normas constitucionales cuya sujeción resulta justamente exceptuada en la situación de excepción.

El primero de los requisitos ha resultado satisfecho en la CE en los enunciados de los arts. 116, 2, 3 y 4 CE que requieren la existencia de un acto normativo expreso que declare los estados de excepción y de sitio, que opera como la condición de la falta de sujeción a las normas constitucionales que se prevé en el art. 55,1 CE bajo la forma de suspensión. Pero también aquella exigencia aparece consagrada en el art. 155,1 CE que condiciona a la adopción de un acto normativo la posibilidad de adoptar las medidas necesarias para la reinstauración de la normalidad a la que se refiere la citada disposición.

El segundo de los requisitos expuestos, la limitación de la vigencia de la excepcionalidad y su consecuente reversibilidad, se aprecia en el art. 116,3 CE que determina que el estado de excepción no podrá exceder de treinta días, que solo podrán ser prorrogables por otro plazo de idéntica duración. En lo que se refiere al estado de sitio, el art. 116,4 CE dispone que su declaración determinará su duración, sin que se defina dicho plazo, algo que la CE debiera haber regulado para evitar la absorción de la normalidad por la excepcionalidad.

El art. 155,1 CE también ha introducido límites a la vigencia de la situación de excepción. Sin embargo, en este caso la CE no se ha basado en el modelo de limitación temporal que se encuentra presente en el art. $116 \mathrm{CE}$ sino en el de limitación finalista. El enunciado del art. 155,1 CE determina que la vigencia de las medidas necesarias que han sido adoptadas tras un acto normativo expreso

47 Hay que reconocer que no han faltado destacadas teorías que han intentado realizar una construcción sobre los límites del estado de excepción, que ha de estar vinculada al respeto al poder constituyente del pueblo y el principio de soberanía popular J. HECKEL, «Diktatur, Notverördnungsrecht, Verfassungsnotstand», Archiv des öffentliches Rechts, n. ${ }^{\circ}$ 61, 1932, pp. 317 y ss. Sin embargo, tales límites, como su propia construcción, resultan inaprehensibles.

48 Ese es el denominado problema del abuso, al que alude A. JAKAB, European Constitucional Language, op. cit., p. 321. 
solo se extiende hasta que se logre la función de la situación de excepción: la instauración de la normalidad identificada con el cumplimiento de las obligaciones infringidas y en la protección del interés general del España.

El tercero de los requisitos para distinguir excepcionalidad y normalidad es la limitación de las normas constitucionales de cuya sujeción dispensa la declaración de la situación de excepción. Este es seguramente el más relevante para evitar que la normalidad quede del todo absorbida en la excepcionalidad, legitimando la total falta de sujeción a aquélla. Este requisito queda adecuadamente satisfecho en el enunciado art. 55,1 CE que limita la falta de sujeción solo a ciertas normas que regulan derechos fundamentales cuando se declaren los estados de excepción y de sitio de los arts. 116,3 y $4 \mathrm{CE}$. Quiere ello decir que la normalidad rige también en la excepcionalidad.

Mayores problemas plantea en ese sentido el enunciado del art. 155,1 CE que autoriza al Estado central adoptar las medidas necesarias, sin que se precise cuáles son las concretas normas a cuya sujeción dispensa la declaración de la situación de excepción. Pareciera así que la necesidad autoriza en el art. $155 \mathrm{CE}$ a la adopción de todo lo necesario, sin que se imponga la sujeción a ninguna norma constitucional. Habría que plantearse, por lo tanto, si no llevaría razón de algún modo la posición de afirmó que el art. 155 CE podría suponer la plasmación de una cláusula de plenos poderes ${ }^{49}$. Este quizás sea el más importante argumento para poder llegar a ver en aquella disposición la plasmación de la teoría sobre el estado de excepción. Teoría que, en supuesta coherencia con ello, el TC habría parecido avalar, como ha quedado dicho, en la STC 89/2019 al erigir la necesidad en parámetro de interpretación de la cláusula relativa a las medidas necesarias.

\section{LA TEORÍA DEL DERECHO DE EXCEPCIÓN Y LA JURIDIFICACIÓN DEL PRINCIPIO DE NECESIDAD}

\section{El fundamento del principio de necesidad}

Tres características son las que quizás puedan definir las teorías del derecho de excepción, - diametralmente opuestas a las que inspiraron las doctrinas del estado de excepción—: a) la identificación entre Estado y derecho, b) la exigencia de que el derecho deba de regular la situación de excepción y, por tanto, c) la plena juridificación del principio de necesidad. Estas construcciones han criticado las doctrinas del estado de excepción, como se ha visto con anterioridad, calificándolas como un razonamiento político o de derecho natural ${ }^{50}$ o consideraciones

49 Véase P. Cruz Villalón, «La protección extraordinaria del Estado» en A. Pedrieri y E. García de Enterría (edits.), La Constitución Española de 1978, Cívitas, Madrid, 1984, p. 714.

50 H. Kelsen, Allgemeine Staatslehre, op. cit., p. 157. 
políticas revestidas en forma de norma jurídica ${ }^{51}$. También como una quiebra del principio una ruptura jurídica nunca puede ser jurídica ${ }^{52}$ o que junto a la Constitución jurídico-positiva existe una Constitución metaposititiva y metajurídica ${ }^{53}$.

El presupuesto teórico del que parten estas construcciones, la identificación entre Estado y derecho es el que, sin duda, mejor puede contribuir a la distinción entre excepcionalidad y normalidad, requerida, como se ha visto, por la función de la excepción. Distinción que resultaba difícil en el modelo de estado de excepción. Pues bien, como resultado de esta identificación entre Estado y derecho, las doctrinas sobre el derecho de excepción partirán de que el derecho ha de regular plenamente la situación de excepción. Una regulación que sería el objeto de una Constitución de excepción o de una Constitución extraordinaria ${ }^{54}$. Tesis que ha sido asumida en la literatura española ${ }^{55}$.

La Constitución de excepción tendría que regular, en primer lugar, el supuesto de hecho de la situación de excepción, es decir, definir cuándo surge la necesidad de preservar la eficacia del Estado. Dicha necesidad ha sido definida a partir de su visión formalizada del objeto del derecho constitucional. En efecto, si éste desempeña la función de regular las condiciones de creación y de aplicación de las restantes normas del sistema jurídico, la necesidad de preservar el Estado surgiría jurídicamente ante situaciones que menoscaben la eficacia de tales funciones ${ }^{56}$. Esto constituiría la situación excepción por antonomasia o excepción en sentido estricto ${ }^{57}$.

Lo cierto es que este modelo de excepción puede verse en el orden constitucional español. En concreto, en el art. 155,1 CE, el supuesto de hecho del poder de coerción se identifica con un menoscabo de las funciones estatales de creación y de aplicación de normas. Pero también el de los estados de excepción y de sitio

51 Z. Giacometti, Das Staatsrecht der Schweizerischen Kantone, op. cit., p. 510.

52 A. Merkl, Allgemeines Verwaltungsrecht, Julius Springer, Wien und Berlin, 1927, p. 167.

53 F. Koja, Allgemeine Staatslebre, op. cit., p. 398.

54 F. Koja, Der Staatsnotstand als Rechtsbegriff, op. cit., p. 14 y Z. Giacometti, Das Staatsrecht der Schweizerischen Kantone, op. cit., p. 508.

55 Véase de nuevo P. Cruz Villalón, Estados excepcionales y suspensión de garantías, op. cit., p. 19. También C. López Garrido, Decisiones excepcionales y garantía jurisdiccional de la Constitución, Marcial Pons, Madrid, 2021, p. 30 y ss.

56 Véase Z. Giacometтi, Das Staatsrecht der Schweizerischen Kantone, op. cit., p. 510, F. Koja, Der Staatsnotstand als Rechsbegriff, op. cit., p. 20. Entre dichas situaciones se ha aludido a la ocupación militar del territorio del Estado, a la insurrección interna o el fracaso de la legislatura parlamentaria (F. KoJA, op. cit., p. 21). Sin embargo, ha habido posiciones que han justificado el surgimiento de la necesidad solo en el caso de menoscabo de la eficacia de la función legislativa, no siendo relevantes los atentados contra otras funciones estatales, véase al respecto F. Ermacora, Allgemeine Staatslebre, vol. II, op. cit., p. 860.

57 Se aprecia aquí cómo las teorías sobre el derecho de excepción han estado notablemente influidas por el positivismo normativista kelseniano. Después de los primeros intentos de juridificación, que se remontan al periodo de la Constitución de Weimar de 1919 — más adelante se hablará sobre ellos—, han sido, sobre todo, a los autores austriacos a los que se debe el modelo actual de jurifidificación de la excepción. Entre ellos, F. Koja, F. Ermacora o A. Merkl, aquí citados. Z. Giacometti ha representado en Suiza uno de los mayores exponentes del positivismo. 
de los arts. 116, 3 y 4 CE, según se ha regulado en los arts. 13 y 32 LOAES, que se refieren a aspectos relacionados con la garantía de la eficacia de las funciones de producción y de aplicación del orden jurídico. Sin embargo, parece que no respondería a este modelo el estado de alarma del art. 116,2 CE, tal y como ha sido regulado, al menos, por el art. 4 LOAES $^{58}$.

Éste sería, en principio, más compatible con lo que las teorías del derecho de excepción han denominado críticamente una excepción en sentido amplio, una situación de excepción social ${ }^{59}$. Este modelo ha sido, en realidad, más propio de la teoría del estado de excepción, al que se ha llegado a partir del desarrollo una doctrina sobre los fines de Estado vinculada, sobre todo, a la tutela de las condi-

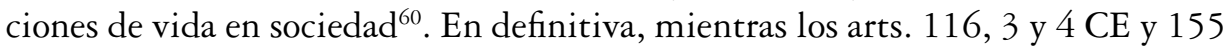
CE consagrarían un modelo de excepción en sentido estricto, el art. 116,2 CE plasmaría una excepción en un sentido amplio. Esta distinción, como se verá, podría explicar las distintas consecuencias jurídicas del principio de necesidad en la CE de 1978.

La Constitución de excepción, además del supuesto de hecho de la necesidad, tendría que regular, en segundo lugar, sus dos consecuencias jurídicas: a) la necesidad crea sus propias reglas y b) la necesidad no conoce reglas. En lo relativo a la primera, la Constitución de excepción debería regular nuevos órganos y procedimientos de creación y de aplicación de normas para afrontar la situación excepcional, y a través de los que se apruebe una regulación jurídica basada en la necesidad ${ }^{61}$. Y ello ante la insuficiencia de los órganos y de los procedimientos de la denominada Constitución de la normalidad, como reconoce el art. 1,2 LOAES. Esa nueva regulación orgánico-procedimental basada en la idea de necesidad puede verse en los arts. 116 y $155 \mathrm{CE}$.

En lo que se refiere, en segundo lugar, a la segunda consecuencia jurídica de la necesidad: la necesidad no conoce reglas, la Constitución de excepción tendría que definir cuáles son los contenidos — vigentes en las situaciones de normalidad- que podrían ser excepcionados de su sujeción con la introducción de la

58 Véase J. M. Lafuente Balle, «Los estados de alarma, excepción y sitio (y II)», Revista de Derecho Político, n. ${ }^{\circ}$ 31, 1990, p. 29 y ss. Más recientemente, y poniendo de manifiesto su carácter bifronte, C. GARRIDO LópEz, «La naturaleza bifronte del estado de alarma y el dilema limitación-suspensión de derechos», Teoría y Realidad Constitucional», n. ${ }^{\circ} 46,2020$, p. 373.

59 Véase F. Koja, Der Staatsnotstand als Rechtsbegriff, op. cit., p. 26.

60 En que se refiere a las teorías clásicas, puede verse ejemplificativamente cómo el desarrollo de una diferente teoría de los fines del estado ha conducido a un diferente fundamento del principio de la necesidad en R. Von Hiering, Der Zweck im Recht, Band. I, op. cit., p. 321, así como C. G. Biener, Die Bestimmung der Kaiserliche Macht-Vollkommenheit in der Teutschen Reichs-Regierung, op. cit., p. 74. En la literatura más actual, diferentes autores han incluido en ese modelo de excepción social, disturbios, hambrunas, huelgas de funcionarios, emergencia económica y financiera, conflictos laborales, epidemias, catástrofes naturales. Véase, entre otros, T. Maunz, Deutsches Staatsrecht, CH Beck, München, 1977, p. 203, K. Hesse, Grundzüge des Verfassungsrechts der Bundesrepublik Deutschland, CF Müller, Karlsruhe, 1972, p. 281.

61 Véase H. KELSEN, «Der Staat als Integration» en idem., Drei Kleine Schriften, Scientia, Aalen, 1994, p. 81, Z. Giacometti, Das Staatsrecht der Schweizerischen Kantone, op. cit., 510. 
nueva regulación basada en la necesidad aprobada por los órganos y los procedimientos previstos en la Constitución de excepción ${ }^{62}$. Esa es la función que cumple justamente el art. 55,1 CE, que permite la suspensión de ciertos derechos fundamentales en el caso de que se declaren los estados de excepción y de sitio de los arts. 116,3 y $4 \mathrm{CE}$.

Desde la óptica de las teorías del derecho de excepción, quizás sería posible encontrar una posible explicación a por qué el principio la necesidad no conoce reglas del art. 55,1 CE es la consecuencia jurídica del principio de necesidad que legitima la creación de sus propias reglas en el estado de excepción y de sitio de los arts. 116,3 y 4 CE y no del de alarma del art. 116,2 CE. Lo sería porque los arts. 116,3 y 4 CE regularían materialmente el supuesto de hecho de la necesidad en sentido estricto, algo que no hace el art. 116,2 CE. Sin embargo, más adelante se verá cómo ni el supuesto de hecho ni las consecuencias jurídicas del principio de necesidad pueden construirse desde su sentido material.

\section{Disfuncionalidades de las teorías del derecho de excepción}

A pesar de los intentos por corregir las disfuncionalidades de la construcción originaria del estado de excepción, las teorías del derecho de excepción también acabarán llegando a resultados incompatibles con su función. Sus disfuncionalidades han sido el resultado, sobre todo, de intentar juridificar en todos sus extremos la situación de excepción ${ }^{63}$. Y es que, cuando eso es así, se corre el riesgo de tener que recurrir a criterios metapositivos para tener que garantizar el adecuado ejercicio de la función de la situación de excepción. Eso es lo que ha reconocido quizás una de las más destacadas contribuciones teóricas del derecho de excepción.

Como se ha afirmado, si las previsiones de la Constitución de excepción son insuficientes ... para afrontar una crisis y salvaguardar el Estado debiera hacer necesario el tránsito hacia la ilegalidad ${ }^{64}$. Parecería, entonces, ser cierto lo que trató de demostrar críticamente la literatura de cómo ni siquiera las teorías sobre el derecho de

62 Véase F. KojA, Der Staatsnotstand als Rechtsbegriff, op. cit, p. 63 y ss.

63 Véase, en este punto, el interesante debate teórico mantenido en las siguientes obras, en las que se defendía, respectivamente, la necesidad de predeterminar en todos sus extremos el supuesto de hecho de la excepción y la imposibilidad de que el ordenamiento jurídico deba de proceder a ello. Véase G. LüBBE-WOLFF, «Rechtsstaat und Ausnahmerecht: Zur Diskussion über die Reichweite des $\$ 34$ StGB und über die Notwendigkeit einer verfassungsrechtlichen Regelung des Ausnahmezustandes», Zeitschrift für Parlamentsfragen, Vol. 11, n. ${ }^{\circ}$ 1, 1980, pp. 110 y ss. Por otro, véase la obra ya citada en este trabajo E.-W. BöcKENFÖRDE, «Das verdrängte Ausnahmezustand», op. cit., p. 1881 y ss.

64 F. KojA, «Staatsnotstand als Rechtsbegriff», Österreichische Juristen Zeitung, 1975, p. 209. Nótese que esta es una obra anterior del autor, respecto de su teorización publicada en 1979. De esta contradicción que manifestaba su trabajo de 1975, que defendía que en caso de que las previsiones de la Constitución fuesen insuficientes para preservar la existencia del Estado, habría que recurrir a la ilegalidad, ha sido percibida recientemente por FiSTER, $\mathrm{M}$ «Staatsnotstandrecht in Österreich» en A. Zwitter (edit.), Notstand und Recht, Nomos, Heidelberg, 2012, p. 160. 
excepción han sido capaces de juridificar del todo la situación de excepción ni desvincularla de la idea metapositiva de necesidad que inspiró su construcción originaria $^{65}$. Quizás, por ello, habría que dar la razón a quienes defendieron que la juridificación de la excepción encierra tras de sí una irresoluble paradoja ${ }^{66}$.

Sin embargo, lo cierto es que habría que reparar en una cuestión. Si el recurso a la idea metapositiva de necesidad surge — así se afirmó_- cuando las previsiones del derecho son insuficientes para procurar una defensa efectiva del Estado ${ }^{67}$, ello tendría que conducir a la conclusión de que la plena juridificación de la idea

65 Efectivamente, esa ha sido la principal conclusión que defendió en su trabajo. HüBER, E.-R «Zur Lehre vom Verfassungsnotstand in der Staatstheorie der Weimarer Zeit», ya citada. Y efectivamente, el estudio de las doctrinas desarrolladas durante la vigencia de la Constitución de Weimar parecen avalar su posición. El problema interpretativo que planteaba el art. 48,2 de la Constitución de Weimar era si debía de entenderse como la plasmación constitutiva o declarativa del principio de necesidad. Quienes defendieron la teoría del estado de excepción entendieron que el art. 48,2 del texto constitucional era la plasmación declarativa del principio metapositivo de necesidad y, por tanto, aquella disposición no agotaba las facultades destinadas a salvaguardar el Estado. Por ello, en el caso de que las medidas previstas en el art. 48,2 fueran insuficientes para ello, siempre cabía la posibilidad de recurrir aquel principio. Véase Schмiтt, C, «Die Diktatur der Reichspräsidenten», Veröffentlichungen Der Vereinigung Der Deutschen Staatsrechtslehrer, núm 1, 1924, p. 83. Las teorías del estado de excepción interpretaron la cláusula relativa al orden y a la seguridad pública del art. 48,2 en un sentido restrictivo, identificándola con la doctrina del estado policía, relacionándola con desórdenes públicos. Por lo tanto, los problemas de parálisis parlamentaria que acaecieron durante los últimos años de vigencia de la Constitución de Weimar no cayeron dentro del supuesto de hecho del art. 48,2, sino que suponían un atentado contra la Constitución material de la sociedad. Ello condujo a dos consecuencias. La primera, que el Reichspräsident podría aprobar disposiciones legislativas, que no amparaba el art. 48,2, sino la idea de necesidad de salvaguardar la Constitución material de la sociedad. En segundo lugar, y precisamente porque dichas disposiciones legislativas no encontraban su fundamento en el art. 48,2, no estaban sometidas al control parlamentario del art. 48,3, solo predicable de las medidas adoptadas en aplicación del art. 48,2. Véase al respecto la destacada contribución de Heckel, J, «Diktatur, Notverördnungsrecht, Verfassungsnotstand, op. cit., p. 269, 311 y ss.

Sin embargo, y frente a esas posiciones, las posiciones positivistas imperantes en Weimar, entendieron que el art. 48,2 debía de considerarse como el fundamento y el límite de los poderes excepcionales. Tal disposición constituía, por tanto, la plasmación jurídica constitutiva de la idea de necesidad, por lo que el recurso a cualquier criterio metapositivo se encontraba prohibido (véase las dos principales posiciones de la época representadas por Anschütz, G., Die Verfassung des deutschen Reichs vom 11. August 1919, Scientia, Aalen, 1987, p. 277 y por R. Thома, «Der Vorbehalt der Legislative und das Prinzip der Gesetzmässigkeit» en G. Anschütz y R. Thома (edits.), Handbuch des deutschen Staatsrechts. Band II, JCB Mohr, Tübingen, 1932, p. 231). También al respecto H. Nawiasky, «Die Auslegung des Art. 48 der Reichsverfassung», Archiv des öffentlichen Rechts, vol. 48, n. ${ }^{\circ} 1,1925$, p. 55. Sin embargo, si no les hizo falta recurrir a la idea metaposiva de necesidad fue gracias a una interpretación verdaderamente extensiva de la cláusula relativa al orden y a la seguridad públicas art. 48,2, que excedía con creces de lo previsto en tal disposición. Véase M. STOLLEIS, Geschichte des öffentlichen Rechts in Deutschland, vol. II, CH. Beck, München, 1999, p. 116. Su supuesto de hecho no quedaba definido solo con arreglo a la doctrina del estado política, sino que en él también encontraron cobertura las distorsiones en el ejercicio de las funciones estatales, lo que las anteriores doctrinas sobre el estado de excepción ampararon en el principio metapositivo de necesidad. Por ello acabaron amparando a partir del en el art. 48,2 las mismas consecuencias que las teorías sobre el estado de excepción acabarían afirmando con recurso al derecho metapositivo. En particular, la posibilidad de que el Reichspräsident pudiera aprobar ordenanzas legislativas y, consecuentemente, la posibilidad de regular materias sometidas a reserva de ley. Véase Anschütz, G., op. cit., p. 284.

66 Véase G. Agamben, Estado de excepción. Homo sacer II, I, op. cit., p. 59 y ss.

67 Véase KojA, F., «Staatsnotstand als Rechtsbegriff», op. cit., p. 209. 
de necesidad — evitando tener que recurrir a criterios metapositivos - se encontraría entonces condicionada a la previsión una regulación eficaz para preservar la existencia del Estado ${ }^{68}$. En este punto, para hacerlo posible quizás fuera de interés la teoría de lagunas en el derecho que defendieran paradójicamente las doctrinas del derecho de excepción.

Y es que si lo que define la situación excepción es responder justamente frente a una situación excepcional e imprevisible, una Constitución que pretenda dispensar una tutela eficaz del Estado no debería predeterminarla en todos sus extremos ${ }^{69}$. Esta existencia de las lagunas, como exigencia teórica para el eficaz ejercicio de la función de la excepción, ha sido compartida por la doctrina española ${ }^{70}$. Y tal exigencia es posible verla además en la CE de 1978. El enunciado del art. 116 CE no define qué debe de entenderse por alarma, excepción o sitio, ni tampoco cuáles deben de ser las medidas para afrontar tales estados excepcionales y recobrar la normalidad ${ }^{71}$.

Por su parte, el enunciado art. 155,1 CE sí ha querido definir el supuesto de hecho y las consecuencias jurídicas del poder de coerción estatal, pero lo ha hecho con un grado de abstracción tal que permite que puedan encontrar encaje en ella una pluralidad de situaciones y medidas. Sin embargo, esta existencia de lagunas en el derecho de excepción necesaria para el adecuado ejercicio de su función lleva, de manera paradójica, a lo que ha de considerarse uno de los elementos estructurales: el rango infraconstitucional de la norma que define el supuesto de hecho y, sobre todo, de sus consecuencias jurídicas.

Esto es lo que se aprecia en el art. 116,1 CE que prevé que las lagunas que presenta el enunciado constitucional deban de ser colmadas por el legislador. La ley aparece como el escalón intermedio entre el art. 116 CE y el acto normativo expreso que procede a la declaración de la excepción. Por su parte, el art. 155 CE no delega en el legislador la función de colmar las lagunas del supuesto de hecho y las consecuencias jurídicas del poder de coerción, sino que la lleva a cabo directamente el acto normativo que declara la situación de excepción ${ }^{72}$.

68 Cfr. Böckenförde, E.-W., «Ausnahmerecht und demokratischer Rechtsstaat», op. cit., p. 265.

69 Véase E.-W. BöcKenförde, E.-W., «Das verdrängte Ausnahmezustand», op. cit., p. 1885.

70 Véase J. J. Solozábal Echavarría, «Algunas consideraciones constitucionales sobre el estado de alarma» en Biglino Campos, P., y Durán Alba, J. F., Los efectos horizontales de la Covid-19 en el sistema constitucional: estudios sobre la primera oleada, Fundación Giménez Abad, Zaragoza, 2021, p. 22 y ss.

71 Sí cabría probablemente deducir del enunciado del art. 116 CE una visión gradualista de dichos estados, pero, desde luego, no su contenido. Así lo señaló ya Cruz Villalón, P., «El nuevo derecho de excepción», Revista Española de Derecho Constitucional, vol. II, n. ${ }^{\circ}$ 1, 1981, p. 95.

72 Sin embargo, el modelo adoptado por el art. 116 CE de remitir al legislador la función de concretar las lagunas del derecho constitucional de excepción podría correr el riesgo de rellenarla por completo, negando el necesario margen de decisión que ha de tener quien decide sobre la excepción. Parece que dicho margen ha sido garantizado por la LOAES, al regular los estados de excepción y de sitio (arts. 13,1 y 32,1). Sin embargo, habría que plantearse si ese margen de decisión lo ha respetado el art. 4 LOAES al predeterminar en todos sus extremos qué deba de considerarse como estado de alarma. Lo cierto es que no han faltado críticas en la doctrina a ese respecto. Véase C. GARrido LópEZ, C., «Las limitaciones como derecho del derecho constitucional de excepción» en C. Garrido López, C. (coord.), Excepcionalidad y derecho: el estado de alarma en España, Fundación Giménez Abad, Zaragoza, 2021, p. 26. 
Hasta aquí se ha tratado de demostrar cómo la principal disfuncionalidad en la que incurre la teoría sobre el derecho de excepción ha sido proponer su plena juridificación. Y eso se aprecia, además, en lo que ha de considerarse su más directa consecuencia: la distinción dentro de la misma Constitución entre la Constitución de excepción y la Constitución de la normalidad. Según dichas doctrinas, la función de la Constitución de excepción sería supuestamente definir las condiciones bajo las cuales la Constitución de la normalidad debería de ser aplicada. De manera, por cierto, muy similar a la relación que existe entre Constitución y ley constitucional en las doctrinas sobre el estado de excepción ${ }^{73}$.

Esa es la función que parece haber asumido la literatura española a la hora de interpretar el concepto suspensión del art. 55,1 CE en clave de aplicabilidad, como se ha visto con anterioridad. Dicha disposición, que integraría la Constitución de excepción, definiría las condiciones bajo las cuales las normas de la Constitución de la normalidad — de la que formarían parte supuestamente los derechos a los que se alude en el art. 55,1 CE— podrían ser aplicadas. Sin embargo, habría que plantearse si ello no resultaría, de alguna forma, una contradicción en sus propios términos.

En efecto, si la Constitución, como han defendido las teorías del derecho de excepción, es la norma que regula las condiciones de creación y aplicación de otras normas - recuérdese que de ahí han derivado el supuesto de hecho de la excepción-, la verdadera Constitución tendría que ser la Constitución de excepción. Y no lo sería la Constitución de la normalidad. Sin embargo, habría que preguntarse si ello podría resultar coherente con el concepto de Constitución como norma suprema que ha sido asumida por la CE de 1978, en la que todas sus normas poseen el mismo rango jerárquico. Resultaría difícil poder justificar cómo alguna de sus normas, aun siendo supremas, pueden seguir siendo válida y no desplegar ninguna consecuencia jurídica, lo que sucedería supuestamente con los derechos a los que se refiere el art. 55,1 CE. Esto sería, sobre todo, aplicable a la tesis que ha entendido que el art. 55,1 CE produce una desconstitucionalización.

En realidad, esa es la verdadera paradoja en la que incurre el derecho de excepción: tratar de juridificar dentro de la misma Constitución, la Constitución de la normalidad y la Constitución de la excepción —una suerte de Constitución en miniatura $-{ }^{74}$. Es decir, la regla y la excepción que supone su propia negación ${ }^{75}$. Esta

73 Es probable que el hecho de que las doctrinas del derecho de excepción nunca hayan podido prescindir de la existencia de dos constituciones exprese, en el fondo, una cierta influencia de la idea metapositiva de necesidad. Y venga ello a avalar la posición que frecuentemente ha planeado sobre los intentos de juridificar la originaria doctrina sobre el estado de excepción de que juridifica, en realidad, algo injuridificable. En no pocas teorías sobre el derecho de excepción que proponen su visión plenamente formalizada, ha sido posible ver cómo se mantiene que la Constitución de excepción permitiría suspender o, lo que resulta más controvertido, infringir (!!!!) las normas de la Constitución de la normalidad, GiacometTi, Z., Das Staatsrecht der Schweizerischen Kantone, op. cit., 510.

74 Véase Ermacora, F., Allgemeine Staatslehre, vol. II, op. cit., p. 863.

75 Las teorías sobre el derecho de excepción han tratado de responder frente a las críticas vertidas contra ellas que les han achacado que no resulta posible la plena juridificación de la excepción. Que ésta debe de 
paradoja, como se ha visto, solo puede resolverse quebrando, por así decir, "por arriba», el concepto de Constitución del que se parte. Infringiendo, en definitiva, la máxima que paradójicamente defendieron las teorías sobre el derecho de excepción para criticar las doctrinas sobre el estado de excepción: que una ruptura jurídica nunca puede ser jurídica ${ }^{76}$.

Pero la paradoja se resuelve cuando se acepta la tesis antes expuesta acerca de la necesaria existencia de lagunas en el supuesto de hecho y, sobre todo, en las consecuencias jurídicas del derecho de excepción, indispensables para el adecuado ejercicio de su función. Unas lagunas que han de ser colmadas a través de normas de rango infraconstitucional. Ese es el auténtico derecho de excepción. La función de la única Constitución existente, la norma verdaderamente, suprema - la Constitución de la normalidad - sería prever las condiciones de su propia derogación tan pronto se apruebe el derecho infraconstitucional de excepción que, por su propia naturaleza, en sus consecuencias jurídicas, resulta materialmente inconstitucional.

En consecuencia, regla y excepción se encuentran plasmadas en normas de distinto rango jerárquico, y la regla constitucional deja de ser válida tan pronto se apruebe la excepción introducida por una norma de rango infraconstitucional que implica su propia negación. Por ello, el concepto de suspensión del art. 55,1 CE no puede entenderse coherentemente en términos de aplicabilidad, sino de validez, esto es, de derogación ${ }^{77}$. El problema es si resulta posible encontrar en la CE 1978 el apoyo normativo necesario para mantener esta construcción. Como se verá seguidamente, podrían existir argumentos para poder defender tal resultado.

\section{LA CONSTRUCCIÓN CONSTITUCIONALMENTE ADECUADA DEL PRINCIPIO DE NECESIDAD EN LA CE}

\section{El principio necesidad no conoce reglas como poder de derogación temporal de normas constitucionales}

Como se ha intentado demostrar, el concepto de Constitución como norma suprema lleva seguramente a entender la excepción justamente como una excepción

encontrarse fuera del sistema jurídico (en la idea metajurídica de necesidad) y que el derecho de ocuparse de regular únicamente la normalidad. Frente a ello se ha afirmado que «todo el derecho no es más que un sistema de reglas y excepciones», Koja, F., Allgemeine Staatslehre, op. cit, p. 398. Y ello seguramente es cierto. Pero quizás no lo sea que la regla y la excepción puedan encontrarse en normas del mismo rango jerárquico.

76 Véase Merkl, A., Allgemeines Verwaltungsrecht, op. cit., p. 167.

77 Hay que reconocer que en la doctrina española se han podido llegar a ver ciertas posiciones que han dejado entrever que el problema que plantea una concepción juridificada del derecho de excepción debe de resolverse en términos de derogación y, no aplicabilidad. Desde luego, quien más se aproximado a esta idea ha sido, desde un punto de vista teórico, el brillante trabajo de V. Álvarez GARCía, El concepto de necesidad en derecho público, op. cit., p. 308 y ss. También ha podido entreverse de alguna manera en el trabajo de GARrido López, C., «Las limitaciones como derecho del derecho constitucional de excepción», op. cit., p. 16. Sin embargo, falta probablemente en ellas el apoyo normativo para sostener tal teoría, que es lo que intentará realizarse seguidamente. 
a la sujeción a ciertas normas constitucionales, traducida formalmente en una derogación — principio la necesidad no conoce reglas — que se produce una vez se introduce una regulación infraconstitucional basada en la idea de necesidad — principio la necesidad crea sus propias reglas_- A pesar de lo que pudiera parecer, lo cierto es a esa conclusión parece que tener que llegarse a partir de una determinada interpretación del Título X CE.

En efecto, el art. 169 CE determina que «No podrá iniciarse la reforma constitucional en tiempo de guerra o de vigencia de alguno de los estados previstos en el artículo 116». Los comentaristas de la Constitución han señalado que la intención del constituyente de 1978 fue garantizar que la reforma solo pudiera llevarse a cabo en situaciones de normalidad ${ }^{78}$. Lo que es tanto como decir que la reforma constitucional no puede realizarse en situaciones de excepcionalidad. Y, en efecto, así es. Desde un punto de vista estrictamente normativo, no sería quizás un sin sentido entender que si la reforma no puede iniciarse es porque las normas constitucionales han perdido validez en los supuestos a los que se refiere el art. $169 \mathrm{CE}^{79}$.

Dicho de otra forma, porque el poder de reforma carecería de objeto como resultado de la declaración formal de una excepción en el derecho constitucional, a través de los actos normativos expresos a los que se refieren los arts. 116, 2, 3 y 4 CE. Por ello, la suspensión a la hace referencia el art. 55,1 CE no podría resolverse en una pérdida de aplicabilidad, como ha entendido principalmente la doctrina. Una norma como la prevista en el art. 169 CE podría tener sentido si se entendiera que la suspensión del art. 55,1 CE implica una pérdida de validez temporal de las normas constitucionales.

Por ello, pareciera que no es el art. 55,1 CE el que debe considerarse la plasmación del principio la necesidad no conoce reglas, sino más bien el art. 169 CE, que es el que le da sentido un sentido constitucionalmente coherente a aquél ${ }^{80}$. Si esto fuera cierto habría que mantener seguramente que dentro de la CE existirían dos poderes de creación de normas constitucionales: el previsto en los arts. 167 y

78 Véase O. Alzaga Villaamil, Comentario sistemático a la Constitución Española de 1978, Marcial Pons, Madrid, 2016, p. 740.

79 La doctrina mayoritaria ha entendido que, conforme al tenor literal del enunciado del art. 169 CE, lo que se prohíbe es que la reforma pueda iniciarse, lo que no permitiría que pudiese tramitarse una ya presentada, véase AláEz CORRAL, B., Los límites materiales a la reforma de la Constitución Española de 1978, CEPC, Madrid, 2000, p. 324. Sin embargo, de aceptarse la tesis aquí expuesta, edificada a partir de una concepción teórica del derecho de excepción en la CE, habría que defender que tampoco podría tramitarse, ya que las normas han quedado derogadas.

80 El Tribunal Constitucional ha aludido precisamente al art. 169 CE en su STC 83/2016, FJ. 7..$^{\circ}$ :Las previsiones del art. 116 CE han de completarse, para una adecuada delimitación del derecho de excepción en el texto constitucional de 1978, con el art. 55.1 CE, que dispone los derechos fundamentales susceptibles de ser suspendidos cuando se acuerde la declaración del estado de excepción o de sitio; con el art. 117.5 CE, que remite a la ley la regulación del ejercicio de la jurisdicción militar en los supuestos de estado de sitio; y, también, con el art. $169 \mathrm{CE}$, que prohíbe que se inicie la reforma constitucional durante la vigencia de alguno de los estados de emergencia». Sin embargo, lo que se encuentra ausente en la citada sentencia es el análisis sistemático de dichas disposiciones. Esto es, determinar cuál es la relación entre el art. 169 CE con el resto de disposiciones que conforman el así denominado derecho de excepción de la Constitución. 
$168 \mathrm{CE}$ y el contemplado en los arts. 116,2, 3 y $4 \mathrm{CE}$. Sin embargo, es claro que ambos poderes tendrían una naturaleza distinta. El poder de los arts. 116,2, 3 y 4 CE no ampararía la posibilidad de sustituir el contenido de una norma constitucional por otro — sí el de los arts. 167 y $168 \mathrm{CE}$ —, sino producir la derogación temporal prevista en el art. 169 CE.

Por eso los actos de los arts. 116, 2, 3 y 4 CE han de tener la consideración de operaciones constituyentes ${ }^{81}$, porque satisfacen la condición de la norma derogatoria ${ }^{82}$ que se prevé en el art. 169 CE. Y precisamente por ello, tal condición se anula una vez finalizada la vigencia del acto que declara la situación de excepción, por lo que las normas derogadas volverían a cobrar validez. Sería éste un supuesto de instauración de la validez de una norma constitucional sin necesidad de un acto de creación normativa, de manera contraria a lo que sucede en los arts. 167 y $168 \mathrm{CE}^{83}$.

Es cierto que esta tesis podría ser muy fácilmente criticable. Sobre todo, si se parte de que la prohibición de incoar la reforma constitucional prevista en el art. 169 CE se afirma en el caso de se declaren no solo los estados de excepción y de sitio, que son los que permiten según el art. 55,1 CE una falta de sujeción a las normas constitucionales, sino también el estado de alarma, al que no es aplicable la suspensión a la que se refiere tal disposición. Sin embargo, bastaría leer la totalidad del enunciado del art. 116 CE para constatar que en él se también contempla una generalmente obviada excepción a la sujeción de normas constitucionales común a los tres estados, adicional a la suspensión prevista en el art. 55,1 CE vinculada solo a los estados de excepción y de sitio.

En efecto, el art. 116,5 CE dispone que «No podrá procederse a la disolución del Congreso mientras estén declarados algunos de los estados comprendidos en el presente artículo, quedando automáticamente convocadas las Cámaras si no estuvieren en período de sesiones. Su funcionamiento, así como el de los demás poderes constitucionales del Estado, no podrán interrumpirse durante la vigencia de estos estados». Parte de la doctrina ha señalado, probablemente con acierto, que tal disposición contiene una excepción al deber de sujeción proclamado en el art. 9,1 CE, al menos, a las normas constitucionales que se refieren al poder de disolución parlamentaria reconocido al presidente del gobierno en el art. $115 \mathrm{CE}$ o el que se produce ex constitutionem en el art. 99,5 $\mathrm{CE}^{84}$.

81 En el sentido que le otorga B. Aláez Corral, «La suspensión general de los derechos fundamentales», op. cit., p. 235 .

82 Véase Kelsen, H., Allgemeine Theorie der Normen, Manz, Wien, 1990, p. 84 y 85.

83 Parece responderse así al interrogante que planteaba la teoría del derecho de excepción «resulta necesario resolver el problema de cuál es el destino que deben de tener aquellas normas, que han sido «desplazadas» por las disposiciones aprobadas en la situación de excepción, si vuelven de nuevo a estar en vigor automáticamente o ello debe de encomendarse a un órgano a través de una decisión expresa», KojA, F., Der Staatsnotstand als Rechtsbegriff, op. cit., p. 63.

84 Véase Cruz Villalón, P., Estados excepcionales y suspensión de garantías, op. cit., p. 132 y $133 . \mathrm{El}$ citado autor habla expresamente de que se produce una suspensión (p. 132), lo que equivaldría a lo previsto en el art. 55,1 CE. 
Eso es lo que permite explicar que el art. 169 CE afirme que no podrá incoarse la reforma de la Constitución cuando estén declarados (todos) los estados excepcionales del art. 116 CE: porque en todos se produce una derogación temporal de normas constitucionales. Sin embargo, para defender que el art. $169 \mathrm{CE}$ ha de considerarse la verdadera juridificación del principio la necesidad no conoce reglas, sería necesario responder a otra pregunta. En particular, por qué la excepción a la sujeción de determinadas normas que permite el art. 155,1 CE — como ha interpretado la doctrina y el $\mathrm{TC}^{85}$ — no aparece también previsto como un límite temporal a la reforma de la Constitución en el art. 169 CE.

Cabría aportar aquí dos posibles explicaciones. La primera, la que quizás más coherente con lo anteriormente expuesto, es que el art. 155 CE no sería la plasmación de un modelo de derecho de excepción — por su propia definición juridificado - sino de un estado de excepción. Y es que, como se ha visto, en su enunciado faltan importantes presupuestos para entender plenamente juridificado el principio de necesidad. El más relevante, la falta de definición de las disposiciones constitucionales de cuya sujeción dispensa la aplicación del art. 155,1 $\mathrm{CE}$, contrariamente a lo que sucede, como se acaba de ver, con los estados de alarma, excepción y sitio del art. $116 \mathrm{CE}$.

La alusión en el art. 155.1 CE a la posibilidad de adoptar las medidas necesarias pareciera legitimar directamente el recurso la idea de necesidad —lo que ha sido avalado por el TC - permitiendo, conforme a los resultados de la teoría del estado de excepción, que cualesquiera normas constitucionales cedan, aquí sí, en su aplicación en todo lo necesario para garantizar la preservación del Estado. Naturalmente, con las difuncionalidades antes reseñadas. Pero también podría aportarse una segunda explicación a por qué el art. 155, 1 CE no aparece como límite positivo temporal a la reforma de la Constitución en el art. 169 CE.

Aun cuando se afirmara que el art. 155,1 CE obedece al modelo del derecho de excepción, como el art. $116 \mathrm{CE} — \mathrm{y}$ pudiera entenderse juridificado el principio de necesidad - la causa de por qué la declaración de la excepción del art. 155,1 CE no aparece como límite positivo temporal a la reforma constitucional en el art. 169 CE podría hallar su explicación en la estructura de nuestro sistema descentralizado. Podría entenderse que el art. 155,1 CE implica una derogación, no al nivel de las normas de rango constitucional, sino legal.

Es decir, lo que permitiría supuestamente el art. 155,1 CE es excepcionar la sujeción a los estatutos de autonomía y a las leyes del art. 150 CE que operan como criterio de distribución competencial entre Estado central y CCAA., que quedarían temporalmente derogados. El enunciado art. 155,1 CE sería, así, supuestamente un derecho de excepción legislativo y no constitucional. Sin

85 Véase Vírgala Foruria, E., «La coacción estatal del artículo 155 de la Constitución», Revista Española de Derecho Constitucional, n. ${ }^{\circ} 73,2005$, p. 100, STC 89/2019, FJ. 4. ${ }^{\circ}$ b. 
embargo, ello plantea el problema de que un derecho de tales características no necesitaría plasmación constitucional y podría estar reconocido al nivel de la ley.

\section{El principio la necesidad crea sus propias reglas. La controvertida definición del ámbito material de la necesidad}

Si una de una de las maneras coherentes de concebir el principio la necesidad no conoce reglas en una Constitución como norma jerárquicamente suprema es entenderlo como un poder de derogación de normas constitucionales - como así se aprecia en el art. $169 \mathrm{CE}$ - es porque ha querido que esa regulación constitucional sea sustituida temporalmente por otra de rango infraconstitucional basada en la idea de necesidad, que legitima la creación de nuevas reglas. Ya se ha visto cómo la verdadera causa del rango infraconstitucional de tal regulación hay que encontrarla en una de las condiciones, ya comentadas, que permiten que la situación de excepción pueda ejercer su adecuadamente función: la necesaria indeterminación de su supuesto de hecho y de su consecuencia jurídica.

Ahora bien, ello no quiere decir que todo el contenido del principio la necesidad crea sus propias reglas deba de tener rango infraconstitucional y, consecuentemente, que la norma constitucional deba renunciar a su regulación. La Constitución de la normalidad, la única norma suprema que puede existir de forma coherente, tendría que regular lógicamente las condiciones de producción de los actos a los que se les atribuye la capacidad de derogar las normas constitucionales. En concreto: a) los órganos y b) los procedimientos a través de los que puede aprobarse la regulación de rango infraconstitucional basada en la idea de necesidad, como condición de derogación de la Constitución.

La CE de 1978 ha procedido a la regulación de este contenido constitucional del principio la necesidad crea sus propias reglas en todos los enunciados que integran el art. $116 \mathrm{CE}$. En primer lugar, la reserva de ley prevista en el art. 116,1 CE, remitiendo a una definición infraconstitucional del supuesto de hecho y de las consecuencias jurídicas de los estados de alarma, excepción y sitio, es decir, del verdadero derecho de excepción. En segundo lugar, la regulación de los órganos y de los procedimientos a los que se les atribuye la potestad de aprobar los actos que satisfacen la condición derogatoria prevista en el art. 169 CE (arts. 116,2- 4 CE).

Sin embargo, llegados hasta aquí, resta por responder una relevante pregunta: cuál es el ámbito material del principio la necesidad crea sus propias reglas, esto es, el ámbito de decisión de la regulación infraconstitucional basada en la idea de necesidad. La respuesta a priori más evidente es que si la excepción en el derecho constitucional no es si no una derogación temporal de las normas constitucionales para permitir que una regulación de rango infraconstitucional ocupe su lugar tendría que afirmarse que la necesidad puede operar creando reglas justamente en los supuestos en los que la CE ha previsto su propia derogación. 
Con todo, definir cuáles son estos ámbitos puede no resultar tan sencillo. El razonamiento seguido hasta aquí identificaba primero las excepciones constitucionales introducidas al deber de sujeción en los arts. 55,1 CE y 116,5 CE que operaban en caso de declaración de los tres estados excepcionales del art. $116 \mathrm{CE}$ y utilizaba posteriormente el art. 169 CE para entender tales excepciones como una derogación temporal. Sin embargo, lo que debe de plantearse es si cabría admitir excepciones a la sujeción a las normas constitucionales, no expresamente previstas, pero sí deducidas de manera implícita. La pregunta se vincula con la relación existente entre los arts. 55,1 y 116,5 CE, de un lado, y el art. $169 \mathrm{CE}$, por otro.

¿Cumple, en realidad, el art. 169 CE solo la función de determinar la naturaleza jurídica — vinculada a la derogación temporal — que poseen las excepciones a la sujeción previstas expresamente en los arts. 55,1 y 116,5 CE? O, ¿es, en realidad, el art. 169 CE la norma que se encarga de definir las excepciones a las normas constitucionales? La pregunta tiene sentido si se tiene en cuenta la falta de simetría entre la derogación que opera el art. 169 CE y las excepciones introducidas en el texto constitucional. El art. 169 CE verifica, es cierto, una derogación normativa producida por las excepciones ya vistas de los arts. 55,1 y 116,5 CE cuando se declaren los estados excepcionales del art. $116 \mathrm{CE}$.

Sin embargo, el art. $169 \mathrm{CE}$ produce supuestamente también una derogación de normas constitucionales cuando se declare la guerra del art. 63,3 CE y, sin embargo, la CE no ha previsto en ese caso excepciones expresas al deber sujeción del art. 9,1 CE. ¿Podría el art. 169 avalar directamente que una normativa infraconstitucional previera excepciones a la sujeción constitucional cuando se declarara la guerra? La pregunta es, en cierta medida, similar a la que plantea la distinción, bien analizada en la literatura, entre la suspensión de derechos prevista en el art. 55,1 CE solo cuando se declaren los estados de excepción y de sitio y la limitación de derechos fundamentales introducida por la LOAES en caso de declaración del estado de alarma del art. 116,2 CE.

A pesar de que no hay en la CE una excepción expresa a la sujeción de los derechos fundamentales para el estado de alarma — sí a las normas constitucionales previstas en los arts. 99,5 y $115 \mathrm{CE}$ a través del art. 116,5 CE) ¿podría derivarse implícitamente ello de algún enunciado constitucional? Sí ello fuera así, sería posible entender que la limitación de derechos fundamentales a la que hace referencia la LOAES podría ir más allá de las facultades atribuidas al legislador ordinario (art. 53,1 CE). Quizás una determinada forma de interpretar la CE llevara a la conclusión que la función del art. 169 CE no es solo definir la naturaleza jurídica — vinculada a una derogación temporal- de las excepciones expresamente previstas en la CE al deber de sujeción. Son quizás éstas las que se encargan de matizar el alcance de la derogación operada por el art. 169 CE.

Como ha apuntado la doctrina, la suspensión de derechos fundamentales a la que se refiere el art. 55,1 CE supondría una desconstitucionalización de sus dimensiones 
objetiva y subjetiva. Con la consecuencia de que si se declararan los estados de excepción y de sitio podría actuarse como si esos derechos no existieran ${ }^{86}$. Y ello permitiría, según esta posición, que el régimen de los derechos fuera sustituido por normas de rango infraconstitucional ${ }^{87}$. Ello podría querer decir, en los términos aquí empleados, que lo que hace el art. 55,1 CE es definir cuál es el alcance de la derogación temporal del art. $169 \mathrm{CE}$, permitiendo que ésta pueda alcanzar a la totalidad de normas (la dimensión objetiva y la subjetiva) que se derivan de los enunciados iusfundamentales a los que alude el art. 55,1 CE ${ }^{88}$.

Si ello fuera así, pudiera llegar admitirse que la limitación de los derechos fundamentales prevista en la LOAES cuando se declarara el estado de alarma del art. 116,2 CE, solo pudiera suponer una derogación parcial de las normas deducidas de sus enunciados iusfundamentales. Podría, quizás afirmarse que la limitación a la que se refiere pudiera implicar una falta de sujeción al deber de respetar el contenido esencial de los derechos fundamentales que integra la dimensión subjetiva, prevista en el art. 53,1 CE, dejándose quizás inalterada su dimensión objetiva. En definitiva, la lectura conjunta de los arts. 55,1 y 169 CE permitiría solo una derogación parcial de las normas deducidas de los enunciados iusfundamentales basada en la idea de necesidad cuando se declarara el estado de alarma previsto en el art. 116,2 $\mathrm{CE}^{89}$.

Hay que reconocer que la posición aquí mantenida puede ser ciertamente criticable. Y, desde luego, ha sido negada por la STC 148/2021, FJ. 3(i) Al fin y al cabo, lo que viene a defender es que el art. 169 CE permitiría directamente una derogación de las normas constitucionales basadas en la idea de necesidad, pudiendo ser total en el caso de los arts. 55,1 CE y 116,5 CE, pero solo parcial en el resto de los supuestos, como el caso del estado de alarma. Sin embargo, habría que plantearse si la LOAES no lo ha llevado a cabo, en realidad, en varias de sus disposiciones una derogación parcial de las normas constitucionales, como ha

86 Véase Aláez Corral, B., «Suspensión general de los derechos fundamentales», op. cit., p. 243.

87 En similares términos que Aláez Corral se ha manifestado Antonio Xiol Ríos en su voto particular a la STC 148/2021 (15): «De este modo, cuando el derecho fundamental se encuentra suspendido el derecho se desconstitucionaliza, por lo que el régimen jurídico de ese derecho no será el constitucionalmente establecido - la norma iusfundamental está temporalmente privada de eficacia_, sino el previsto en ley orgánica que regule el estado de excepción o el de sitio o en la ley orgánica que regule las investigaciones relacionadas con el terrorismo. En consecuencia, cuando está suspendido el derecho fundamental, este derecho no existe como tal y solo tendrá el alcance que le otorguen las leyes orgánicas a las que se remite el art. 55.2 y $116 \mathrm{CE} »$

88 Sin embargo, hay que reconocer que la tesis de Aláez Corral entiende la suspensión como una suspensión de la vigencia de normas constitucionales, «Suspensión general de los derechos fundamentales», $o p$. cit., p. 243.

89 Sin embargo, una parte de la doctrina más autorizada ha entendido que la falta de sujeción a la norma constitucional que impone el respeto al contenido esencial de los derechos fundamentales del art. 53,1 CE sería, en realidad, el contenido del concepto de suspensión de los derechos fundamentales previsto en el art. 55,1 CE. Véase Requejo Rodríguez, P., «¿Suspensión o supresión de los derechos fundamentales?», op. cit., p. 113. Es decir, que el art. 55,1 CE, al menos en los términos aquí empleados, produciría solo la derogación de una de las dos normas deducidas de los enunciados iusfundamentales de los derechos a los que alude el art. 55,1 CE. 
sucedido con las normas que distribuyen territorialmente el poder del Estado. Eso parece haber sido acreditado por la doctrina ${ }^{90}$.

\section{CONCLUSIONES}

El significado de la situación de excepción en el derecho constitucional se ha construido a partir de la idea de necesidad. Las teorías clásicas sobre el estado de excepción han desarrollado esta idea a partir de la distinción entre Estado y derecho. Defenderán que el Estado, ante la necesidad de afrontar situaciones que ponen en peligro su existencia misma y recobrar la normalidad, podrá desasirse temporalmente de la sujeción a las normas del derecho.

Estas doctrinas clásicas permiten, en realidad, deducir cuál es la esencia de la excepción en el derecho constitucional: a) la introducción una regulación basada en la necesidad — principio la necesidad crea sus propias reglas —, b) legitimando, a su vez, una falta de sujeción a las normas del derecho-principio la necesidad no conoce reglas - El problema es que las teorías del estado de excepción no serán capaces de ejercer la función de la excepción, que es excepcionar temporalmente la sujeción al derecho, pero con el fin de recobrar la normalidad.

Y no lo son porque, como consecuencia de la ausencia de una teoría de los límites de la excepción, acabarán fusionando excepcionalidad y normalidad, no siendo capaz de garantizar el retorno a ésta. Lo definitorio del modelo de estado de excepción es autorizar a la adopción de todo lo necesario para la salvaguarda del Estado — principio la necesidad crea sus propias reglas_-, legitimando una falta de sujeción a cualquier norma del derecho — principio la necesidad no conoce reglas-. Parte de estos problemas podrían llegar a verse en el art. $155 \mathrm{CE}$.

Las doctrinas sobre el derecho de excepción sí han sido capaces de construir una teoría de los límites a la situación de excepción como consecuencia de su propuesta de juridificar la idea de necesidad. Cuando esto es así, resulta posible introducir en el orden jurídico los 3 elementos que permiten, en realidad, distinguir la excepcionalidad y la normalidad: a) la previsión de un acto normativo expreso que implique el tránsito de ésta a aquélla, b) la limitación de la vigencia de la situación de excepción, y la reinstauración de la normalidad y c) la definición de cuáles son las concretas normas vigentes en la normalidad, de cuya sujeción queda dispensada al declarar la situación de excepción. Estos elementos se aprecian en los arts. 116 y 155 CE.

Sin embargo, las teorías sobre el derecho de excepción también llegan a resultados contrarios a la función de la excepción, como consecuencia de su intento de

90 Véase Velasco Caballero, F., «Estado de alarma y distribución territorial del poder», El Cronista del Estado Social y Democrático de Derecho, n. ${ }^{\circ}$ 86-87, p. 81, Arroyo GiL, A., «La naturaleza del estado de alarma y su presupuesto habilitante», op. cit., p. 40 . 
juridificar en todos los extremos la idea de necesidad. Tanto su supuesto de hecho como sus consecuencias jurídicas. Esta pretensión de plena jurifidicación de la idea de necesidad ha llevado a distinguir dentro del mismo texto constitucional, una Constitución de excepción y una Constitución de la normalidad. Dejando a un lado que este dualismo no refleja en muchas ocasiones otra cosa que el recurso a la idea metapositiva de necesidad, lo cierto es que ello implica una importante paradoja.

Esta paradoja consiste en regular dentro del mismo documento constitucional la regla y la excepción que implica su propia negación. Una paradoja que solo puede salvarse convirtiendo a la Constitución de excepción en la norma que define las condiciones de aplicabilidad de la Constitución de la normalidad. Esto sería compatible con una interpretación del art. 55,1 CE en clave de aplicabilidad. Sin embargo, si se admite esta consecuencia parece habría que llegar al resultado de que sería la Constitución de excepción, no la de la normalidad, la verdadera Constitución del Estado. Es probable que ello resulte incompatible con el concepto de Constitución como norma jerárquicamente suprema, que solo admite una única Constitución: la de la normalidad.

Pero estos problemas se soslayan si el problema se aborda desde el punto de vista de la función de la excepción. En realidad, una Constitución que pretenda afrontar eficazmente una situación imprevisible y excepcional no debe poder regularla en todos sus extremos. Lo que es excepción y las medidas necesarias para afrontarlas no han de ser decididas por el constituyente, sino por el creador de normas infraconstitucional. Esta es la verdadera naturaleza del derecho de excepción: su rango infraconstitucional.

Lo que debe de regular la Constitución (de la normalidad) son las condiciones bajo las cuales sus normas quedan derogadas (principio la necesidad no conoce reglas) cuando se apruebe una normativa infraconstitucional basada en la necesidad (principio la necesidad crea sus propias reglas). La excepción en el derecho constitucional debe de considerarse, en realidad, un poder de derogación de normas constitucionales. Pero, en tanto es esa su naturaleza, la Constitución sí debe de regular las condiciones bajo las cuáles se produce tal derogación. Esto es, una parte del principio la necesidad crea sus propias reglas debe de tener rango constitucional (las condiciones de creación de los actos que generan la derogación de la Constitución) y otro rango infraconstitucional: la concreción del supuesto de hecho y de las consecuencias jurídicas de la excepción. Algunos argumentos para defender esta construcción podrían llegar a verse en el art. 169 CE.

$$
* * *
$$

TITLE: State and the law of exception. The legal principle necessity knows no law

ABSTRACT: This paper aims to analyze the theories of the state and the law of exception that have tried to explain when and how the state can react to situations that endanger its own existence. The classical theories of the state of exception are unable to accommodate the exception in constitutional law because they are unable to distinguish exceptionality and normality. The theories on the law of exception, although they do 
allow distinguishing exceptionality and normality, reach the paradox of introducing the rule and the exception in the same constitutional text. The aim of this paper is to analyze how a constitutionally adequate construction of the exception in constitutional law can be carried out. Based on the Spanish Constitution.

RESUMEN: Este trabajo pretende analizar las teorias del estado y del derecho de excepción que han tratado de explicar cuándo y cómo puede reaccionar el Estado frente a las situaciones que ponen en peligro su propia existencia. Las teorías clásicas del estado de excepción no son capaces de encontrar acomodo a la excepción en el derecho constitucional porque no distinguen entre excepcionalidad y normalidad. Las teorías sobre el derecho de excepción, a pesar de que sípermiten distinguir excepcionalidad y normalidad, llegan a la paradoja de introducir la regla y la excepción en el mismo texto constitucional. Lo que se pretende analizar es cómo puede llevarse a cabo una construcción constitucionalmente adecuada de la excepción en el derecho constitucional. Con apoyo en la Constitución Española de 1978.

KEY WORDS: theory of the constitution, state of exception, state of emergency, doctrine of necessity, fundamental rights.

PALABRAS CLAVE: teoría de la constitución, derecho de excepción, estado de excepción, estado de emergencia, teoría de la necesidad, derechos fundamentales.

FECHA DE RECEPCIÓN: 30.08.2021

FECHA DE ACEPTACIÓN: 08.10.2021 
